\title{
Incidence and Survival of Hospitalized Acute Decompensated Heart Failure in Four US Communities (from the Atherosclerosis Risk in Communities Study)
}

\author{
Patricia P. Chang, MD, MHS ${ }^{a},{ }^{*}$, Lloyd E. Chambless, PhD ${ }^{b}$, Eyal Shahar, MD, MPH $^{\mathrm{c}}$, Alain G. \\ Bertoni, MD, MPH ${ }^{d}$, Stuart D. Russell, MD ${ }^{e}$, Hanyu Ni, PhD, MPH ${ }^{f}$, Max He, MS ${ }^{g}$, Thomas H. \\ Mosley, PhD ${ }^{\mathrm{h}}$, Lynne E. Wagenknecht, DrPH ${ }^{\mathrm{d}}$, Tandaw E. Samdarshi, MD, MPH ${ }^{\mathrm{h}}$, Lisa M. \\ Wruck, PhD ${ }^{b}$, and Wayne D. Rosamond, PhD ${ }^{i}$
}

aDepartment of Medicine, University of North Carolina, Chapel Hill, North Carolina bepartment of Biostatistics, University of North Carolina, Chapel Hill, North Carolina 'Department of Epidemiology and Biostatistics, University of Arizona, Tucson, Arizona dDepartment of Public Health Sciences, Wake Forest University, Winston-Salem, North Carolina eDepartment of Medicine, Johns Hopkins University, Baltimore, Maryland ${ }^{f}$ Centers for Disease Control and Prevention, National Center for Health Statistics, Hyattsville, Maryland 9Duke Clinical Research Institute, Durham, North Carolina hDepartment of Medicine, University of Mississippi Medical Center, Jackson, Mississippi 'Department of Epidemiology, University of North Carolina, Chapel Hill, North Carolina

\section{Abstract}

\begin{abstract}
Most population-based estimates of incident hospitalized heart failure (HF) have not differentiated acute decompensated heart failure (ADHF) from chronic stable HF nor included racially diverse populations. The Atherosclerosis Risk in Communities Study conducted surveillance of hospitalized HF events (age 255 years) in 4 US communities. We estimated hospitalized ADHF incidence and survival by race and gender. Potential 2005 to 2009 HF hospitalizations were identified by International Classification of Diseases, Ninth Revision, Clinical Modification, codes; 6,168 records were reviewed to validate ADHF cases. Population estimates were derived from US Census data; $50 \%$ of eligible hospitalizations were classified as ADHF, of which $63.6 \%$ were incident ADHF and 36.4\% were recurrent ADHF. The average incidence of hospitalized ADHF was 11.6 per 1,000 persons, aged 255 years, per year, and recurrent hospitalized ADHF was 6.6 per 1,000 persons/yr. Age-adjusted annual ADHF incidence was highest for black men (15.7 per 1,000$)$, followed by black women $(13.3$ per 1,000$)$, white men $(12.3$ per 1,000$)$, and white women (9.9 per 1,000). Of incident ADHF events with heart function assessment (89\%), $53 \%$ had reduced the ejection fraction (heart failure with reduced ejection fraction $[\mathrm{HFrEF}]$ ) and
\end{abstract}

(C) 2014 Elsevier Inc. All rights reserved.

*Corresponding author: Tel: (919) 843-5214; fax: (919) 966-1743. patricia_chang@ med.unc.edu (P.P. Chang).

Supplementary Data

Supplementary data related with this article can be found, in the online version, at http://dx.doi.org/10.1016/j.amjcard.2013.10.032.

Disclosures

The authors have no conflicts of interest to disclose. 
47\% had preserved ejection fraction (heart failure with preserved ejection fraction [HFpEF]).

Black men had the highest proportion of acute HFrEF events (70\%); white women had the highest proportion of acute $\mathrm{HFpEF}(59 \%)$. Age-adjusted 28-day and 1-year case fatality after an incident ADHF was $10.4 \%$ and $29.5 \%$, respectively. Survival did not differ by race or gender. In conclusion, ADHF hospitalization and HF type varied by both race and gender, but case fatality rates did not. Further studies are needed to explain why black men are at higher risk of hospitalized ADHF and HFrEF.

Estimates of incident heart failure (HF) rates ${ }^{1}$ are often based on hospital discharge diagnoses codes that include chronic HF cases and possibly non-HF cases and, thus, may not reflect the actual number of hospitalizations for acute decompensated heart failure (ADHF). Because most HF patients are likely to be hospitalized within 5 years, $17 \%$ because of acute decompensation, ${ }^{2}$ reliable estimates are needed to better understand and track the risk, burden, and outcomes of HF. To assess the impact of clinical management on survival of $\mathrm{HF}$, and the effect of risk factors and their control on HF incidence, it is important to obtain community-based estimates of ADHF events and monitor their changes. Previous studies reported that approximately half of overt $\mathrm{HF}$ cases are heart failure with preserved ejection fraction (HFpEF), ${ }^{3,4}$ but it is unclear if this distribution exists in diverse communities or in similar proportions across race-gender groups. The Atherosclerosis Risk in Communities (ARIC) study monitors prevalence and incidence of hospitalized ADHF in 4 communities. We describe here our first 5-year estimates of validated hospitalized acute decompensated $\mathrm{HF}$ events and case fatality (CF) by race, gender, and $\mathrm{HF}$ types.

\section{Methods}

The 4 ARIC study communities include Forsyth County, North Carolina; Jackson, Mississippi; Minneapolis, Minnesota; and Washington County, Maryland. Average genderand race-specific population estimates for each study community were computed for 2005 to 2009 by extrapolations from the 2000 and 2010 US censuses. The estimated population size aged $\geq 55$ years were Forsyth County, 395,782 (20.8\% black); Jackson, 171,241 (60.9\% black); Minneapolis suburbs, 253,225; and Washington County, 174,414. Because the Minneapolis suburbs and Washington County were predominately white, blacks from these 2 communities were not included in the final analysis.

Community surveillance of hospitalized ADHF began on January 1, 2005. Methods of event ascertainment and classification have been described previously. ${ }^{5}$ Briefly, a stratified random sample of eligible hospitalizations in 2005 to 2009 for HF was selected based on 3 criteria: (1) International Classification of Diseases, Ninth Revision, Clinical Modification (ICD-9-CM) discharge diagnosis codes for HF or HF-related condition (398.91, 402.01, 402.11, 402.91, 404.01, 404.03, 404.11, 404.13, 404.91, 404.93, 415.0, 416.9, 425.4, 428.x, 518.4, and 786.0x) in any position; (2) age 255 years at the time of hospital discharge; and (3) home address within boundaries of the ARIC communities. The sampling varied by ICD-9-CM discharge codes (428 and non-428), field center, gender, and race (by race in Forsyth County and Jackson only) to achieve similar SEs across these groups (https:// www2.cscc.unc.edu/aric/surveillance-manuals). 
Eligible hospitalizations (unweighted $\mathrm{n}=10,500$ ) were abstracted by trained abstractors if the medical record documented any evidence of decompensation or new onset of HF symptoms or any mention by a physician that HF was the reason for hospitalization. Fully abstracted cases (unweighted $n=6,399$ ) were independently classified by computer algorithm or 2 physicians of the ARIC Mortality and Morbidity Classification Committee into 1 of 5 categories as previously described ${ }^{5}$ : definite ADHF, possible ADHF, chronic stable HF, HF unlikely, or unclassifiable. Disagreements were adjudicated by the chair of the Mortality and Morbidity Classification Committee (HF specialist). Definite or possible ADHF required evidence from symptoms, signs, imaging, or treatment of an acute exacerbation, worsening or new onset of symptoms, or other decompensated circulatory state. For the purpose of this report, hospitalized HF classification was categorized as: ADHF (definite or possible ADHF), chronic HF, and no HF (HF unlikely or unclassifiable). ADHF events were further classified as heart failure with reduced ejection fraction (HFrEF; current or most recent left ventricular ejection fraction $[\mathrm{LVEF}]<50 \%$ ), HFpEF (LVEF $250 \%$ or greater), or unclassifiable (unknown LVEF).

An incident ADHF event was defined as a hospitalization for ADHF with no previous hospitalization for HF noted in the medical record. Recurrent ADHF was defined as a hospitalized ADHF event with a previous hospitalization for HF. Vital status of hospitalized HF events within 1 year after discharge was determined by linkage with the National Death Index.

Population-based estimates for each community were computed by age, gender, and race on the basis of intercensal estimates derived by extrapolation from US Census data. After excluding a small number of nonblack minorities $(\mathrm{n}=149)$, few blacks in 2 predominately white communities (Minnesota and Washington County; $\mathrm{n}=81$ ), and 1 with missing sampling information, the final sample included 6,168 hospitalizations with HF screening ICD-9-CM codes for the year 2005 to 2009 . The weighted sample corresponded to 42,413 hospitalizations.

To account for the sampling design, all analyses were weighted by the inverse of the sampling probability. Age-specific rates and their SEs were calculated by Poisson regression. Rates were adjusted for age by direct standardization to the US population in 2000 and are reported as an average per year over the 5 years. Age-adjusted mortality curves were created based on Cox models with age as a covariate. The 28-day and 1-year CF percentages were computed by gender and race. All CF percentages were adjusted for age by the direct method using the ARIC combined hospitalized HF events as the standard; gender-specific percentages were also adjusted for race. Additional multivariable-adjusted regression analyses for $\mathrm{CF}$ included prevalent coronary heart disease, hypertension, diabetes, body mass index, asthma, or chronic obstructive pulmonary disease as covariates.

\section{Results}

Of the $42,413 \mathrm{HF}$-eligible hospitalizations, $41.2 \%$ were validated as ADHF, $9.0 \%$ as chronic $\mathrm{HF}$, and $49.8 \%$ were classified as no HF; the most common ICD-9-CM discharge code was 
428.xx (congestive HF, 89.1\%). Of the validated hospitalized HF events, $82 \%$ were ADHF; $76.7 \%$ had either previous outpatient diagnosis of HF (73.4\%) or treatment for HF (64.9\%).

Of hospitalized ADHF events, $63.6 \%$ were incident hospitalized ADHF (53.2\% of which had previous HF diagnosis) and $36.4 \%$ were recurrent events. Although $92.0 \%$ of those with ICD-9-CM code 428 listed as the primary diagnosis were validated ADHF, $42.3 \%$ of all ADHF events (37.3\% of incident ADHF) had ICD-9-CM code 428 as the first listed diagnosis. Demographic and clinical characteristics were similar between all hospitalized ADHF events and the subset with incident hospitalized ADHF (Table 1). Assessment of heart function either before or during the hospitalization was available in most patients. The most common co-morbidities were hypertension, coronary disease, chronic kidney disease (defined as stage 3 or worse), and diabetes. Of incident ADHF events, $12.3 \%$ were preceded by an acute myocardial infarction or unstable angina. Other possible precipitating factors of incident ADHF, in decreasing order, included atrial fibrillation or atrial flutter (10.7\% of cases with a precipitating factor identified), pneumonia (9.4\%), noncompliance with medications (9.4\%), other infection (9.2\%), noncompliance with diet (4.9\%), excess fluid intake or administration (3.3\%), and stroke or transient ischemic attack (1.2\%).

The incidence of hospitalized ADHF was 11.6 per 1,000 persons, aged 255 years, per year, and the rate of recurrent hospitalized ADHF was 6.6 per 1,000 persons per year. Incidence increased with advancing age in the overall population and in each race-gender group $(\mathrm{p}$ $<0.001$; Table 2). The incidence was higher in men than women overall (age-adjusted $\mathrm{p}$ $<0.001$ ) and for each age group (all $\mathrm{p}<0.001$ ). The rate in blacks was significantly higher than the rates in whites, overall and for all age groups except those $\geq 75$ years ( $p \unlhd 0.005$ ). The age-adjusted incidence of hospitalized ADHF was highest in black men, followed by black women, white men, and white women. Age-adjusted recurrence rates of hospitalized ADHF and age-adjusted hospitalization rates of ADHF showed similar patterns (Figure 1). Rates did not differ significantly by community. When the definition of incident events excluded those with a previous diagnosis of HF (56\%), the incidence estimates were lower, as expected, but the race-gender patterns were unchanged except that differences in rates between all men and all women and between men and women $\geq 75$ years were no longer statistically significant (Supplementary Table 1).

Among incident ADHF cases, mean LVEF was 42.4\% (SE 0.4\%; i.e., mean of the lowest LVEF estimates available), with 53.0\% having HFrEF and 47.0\% having HFpEF (Table 1). For most incident ADHF cases, the etiology of HF was not specifically identified in the chart; however, $15.4 \%$ were ischemic cardiomyopathy, $7.1 \%$ systolic HF/other cardiomyopathy, $5.5 \%$ idiopathic dilated cardiomyopathy, $2.3 \%$ hypertensive cardiomyopathy, $2.3 \%$ diastolic HF, $1.0 \%$ cor pulmonale, and $0.2 \%$ hypertrophic cardiomyopathy. The overall age-adjusted incidence was higher for ADHF from HFrEF (8.31, 95\% confidence interval [CI] 7.35 to 9.28 per 1,000 persons, aged $\geq 55$ years, per year) than for ADHF from $\mathrm{HFpEF}(6.22,95 \%$ CI 5.38 to 7.06 per 1,000 persons, aged 255 years, per year).

Black men had the highest proportion of incident acute decompensated HFrEF events followed by white men, black women, and white women ( $\mathrm{p}<0.001$; Table 3 ). White women 
had the highest proportion of incident acute HFpEF events followed by black women, white men, and black men ( $\mathrm{p}<0.001)$. However, black women had similar or slightly higher proportion of incident HFrEF compared with $\mathrm{HFpEF}(\mathrm{p}=0.22)$. All validated ADHF events showed similar patterns although black women had more acute $\operatorname{HFrEF}(\mathrm{p}=0.002)$.

The age-adjusted CF after an incident hospitalized ADHF was 10.4\% (95\% CI 8.5 to 12.2) at 28 days and $29.5 \%$ (95\% CI 26.9 to 32.0 ) at 1 year. Although the ageadjusted mortality curve over 1 year appears to be higher in white men (Figure 2), this difference was not statistically significant at either 28 days or at 365 days. Figure 3 shows the age-adjusted 28day and 1-year CF by ADHF type, gender, and race-gender groups. CF at 28 days and 1 year was higher after an incident HFrEF event than after an incident HFpEF for most race-gender groups, except for white women who have more HFpEF. There were no differences between race-gender groups. When age-adjusted CF was additionally adjusted for prevalent coronary heart disease, hypertension, diabetes, body mass index, asthma, or chronic obstructive pulmonary disease, $\mathrm{CF}$ estimates were modestly decreased, but there were still no differences between race-gender groups. When recurrent (prevalent) acute HF cases were included, the mortality curves and trends of CF were similar, except the multivariableadjusted 1-year CF was higher in all men with $\operatorname{HFrEF}(33 \%, 95 \%$ CI 29 to 38 ) than in all women with $\operatorname{HFrEF}(25 \%, 95 \%$ CI 20 to $30, \mathrm{p}=0.009)$. When the definition of incident events excluded those with a previous diagnosis of HF, 1-year CF estimates were lower by approximately 5\%, but the race-gender patterns were unchanged.

\section{Discussion}

We found that ADHF hospitalization rates and HF type varied by race and gender, whereas CF did not. The ARIC study is unique because it differentiates ADHF from chronic stable $\mathrm{HF}$, contributing more specificity than older classification criteria (e.g., Framingham) and ICD-9-CM codes. ${ }^{5}$ In addition, the ARIC communities are relatively racially diverse allowing for evaluation of event rates among whites and blacks. Black men had the highest incidence and recurrence rates of hospitalized ADHF, whereas white women had the lowest rates. These findings suggest that black men have more severe HF or less control of their $\mathrm{HF}$, or both, that lead to more frequent hospitalizations.

Also novel is our study demonstrates that there is a disparity in incidence of ADHF by both race and gender. Previous population-based studies of incident HF events ${ }^{6-18}$ demonstrated various methodologic weaknesses, notably, populations of predominantly white participants and inclusion of chronic HF. For example, most studies allowed chronic therapy for HF as sufficient for their definition. ${ }^{11,12}$ The only known large community-based studies to specifically examine rates of hospitalized ADHF did so in mostly white populations (in Worcester, Massachusetts, and Minneapolis-St. Paul, Minnesota). ${ }^{16,19}$ Compared with these previous studies, the incidence of hospitalized ADHF in our population were two- to fourfold higher, which probably reflects our more diverse population or inclusion of patients with previous outpatient history of HF.

Compared with the few epidemiologic studies that included racially diverse populations (Health ABC and MESA studies), our overall findings were similar in that blacks were 
found to have a relatively high incidence of HF. ${ }^{11,12,18}$ The recent study of Medicare beneficiaries based solely on ICD-9-CM discharge codes described similar patterns, with black men having the highest hospitalization rates for HF. ${ }^{20}$ In the Health $\mathrm{ABC}$ and MESA cohorts, where blacks also had the highest incidence of HF, ${ }^{11,18}$ the distribution of HFrEF and HFpEF based on limited LVEF data in these cohorts was similar to our communitybased study. Although other reports have suggested HFpEF accounts for half of the HF burden, $, 3,21-24$ our results show that this proportion may differ by both race and gender, where HFrEF is more frequent among black women, black men, and white men. The explanations may be that blacks or men are more likely to have been hospitalized with HFrEF than their counterparts with HFpEF, or there may be a combination of information bias and selection bias, with HFrEF to be more likely classified as ADHF.

Although $92 \%$ of hospitalizations with primary ICD-9-CM discharge code of 428 were validated ADHF events, only $42 \%$ of ADHF events ( $37 \%$ incident ADHF) had a primary discharge code of 428; and more than half of the ADHF cases had another primary discharge code. The high specificity and low sensitivity of a primary discharge ICD-9-CM code 428 found in this study suggest that HF events identified solely by ICD-9-CM codes may not accurately estimate the rate of HF-related hospitalizations, similar to previous reports. $5,9,17$ Thus, the estimated national statistics of 1,102,000 hospitalizations for $\mathrm{HF}(803,000$ for aged 65 years or older) in 2006, based on the National Hospital Discharge Survey ${ }^{6}$ or the HF hospitalization rates of 1957 to 2845 per 100,000 person-years in Medicare Beneficiaries (1998 to 2008), ${ }^{20}$ may be an underestimate of acute decompensated HF because these surveys were based on ICD-9-CM codes alone.

There have been mixed results regarding survival after hospitalized HF. Estimates from Olmsted County suggested that men have worse survival compared with women, ${ }^{15}$ whereas the recent Medicare survey ${ }^{20}$ and the Organized Program to Initiate Lifesaving Treatment in Hospitalized Patients with Heart Failure (OPTIMIZE-HF) ${ }^{24}$ and Get With The GuidelinesHeart Failure (GWTG-HF) ${ }^{25}$ patient registries suggested that whites had worse survival compared with blacks. A previous report from the ARIC cohort $^{13}$ suggested that survival after hospitalization for HF is worse in blacks compared with whites. Race and gender differences may be related to the cause, $\mathrm{LVEF},{ }^{23,24}$ co-morbidities $^{26}$ and their control, ${ }^{27}$ compliance, and socioeconomic factors including access to care and quality of care. ${ }^{28}$

However, the present findings from ARIC community surveillance add to the uncertainty of whether CF differs by race or gender. One-year CF was $30 \%$ for each race-gender group; this is higher than national estimates of $20 \%$ that are based on more homogenous populations, namely the Framingham Heart Study and Olmsted County. ${ }^{1}$ The lack of race or gender differences in short-term survival in the present study should be confirmed in other diverse population-based studies.

Limitations of this study include, first, that our study population originates from 4 US communities and is restricted to those $\geq 55$ years old and, therefore, does not represent the total US population. Second, our definition of incident hospitalized HF is based on the lack of previous hospitalization for $\mathrm{HF}$ and includes patients with a previous diagnosis of $\mathrm{HF}$ (56\%). Our focus is on HF events that become serious enough to require hospitalization, and 
for these, we look for "first hospitalizations" as we have done for other cardiovascular diseases. ${ }^{29}$ When our definition of incident events excluded those with a previous diagnosis of $\mathrm{HF}$, incidence estimates were lower, as expected, but the trends and inferences were unchanged. Potential precipitating factors were identified by explicit documentation of such in the clinical record, which may be speculative, incomplete, and potentially inaccurate; however, previous reports using similar methods have identified similar precipitants. ${ }^{30}$ Finally, the present study was limited to hospitalized HF and did not include outpatient HF events. Nevertheless, the ARIC study is the first to differentiate hospitalization rates of ADHF from chronic HF in a biracial community-based population and confirms that $\mathrm{HF}$ hospitalization identified solely by $I C D-9$ codes may not accurately estimate the burden of ADHF.

\section{Supplementary Material}

Refer to Web version on PubMed Central for supplementary material.

\section{Acknowledgments}

The authors thank the staff and participants of the ARIC study for their important contributions.

The Atherosclerosis Risk in Communities Study is carried out as a collaborative study supported by National Heart, Lung, and Blood Institute (Bethesda, Maryland) contracts (HHSN268201100005 C, HHSN268201 100006 C, HHSN268201100007 C, HHSN268201100008 C, HHSN268201100009 C, HHSN268201100010 C, HHSN268201100011 C, and HHSN268201100012 C).

\section{References}

1. Roger VL, Go AS, Lloyd-Jones DM, Adams RJ, Berry JD, Brown TM, Carnethon MR, Dai S, de Simone G, Ford ES, Fox CS, Fullerton HJ, Gillespie C, Greenlund KJ, Hailpern SM, Heit JA, Ho PM, Howard VJ, Kissela BM, Kittner SJ, Lackland DT, Lichtman JH, Lisabeth LD, Makuc DM, Marcus GM, Marelli A, Matchar DB, McDermott MM, Meigs JB, Moy CS, Mozaffarian D, Mussolino ME, Nichol G, Paynter NP, Rosamond WD, Sorlie PD, Stafford RS, Turan TN, Turner MB, Wong ND, Wylie-Rosett J. American Heart Association Statistics Committee and Stroke Statistics Subcommittee. Heart disease and stroke statistics—2011 update: a report from the American Heart Association. Circulation. 2011; 123:e18-e209. [PubMed: 21160056]

2. Dunlay SM, Redfield MM, Weston SA, Therneau TM, Hall Long K, Shah ND, Roger VL. Hospitalizations after heart failure diagnosis a community perspective. J Am Coll Cardiol. 2009; 54:1695-1702. [PubMed: 19850209]

3. Redfield MM, Jacobsen SJ, Burnett JC Jr, Mahoney DW, Bailey KR, Rodeheffer RJ. Burden of systolic and diastolic ventricular dysfunction in the community: appreciating the scope of the heart failure epidemic. JAMA. 2003; 289:194-202. [PubMed: 12517230]

4. Bursi F, Weston SA, Redfield MM, Jacobsen SJ, Pakhomov S, Nkomo VT, Meverden RA, Roger VL. Systolic and diastolic heart failure in the community. JAMA. 2006; 296:2209-2216. [PubMed: 17090767]

5. Rosamond WD, Chang PP, Baggett C, Johnson A, Bertoni A, Shahar E, Deswal A, Heiss G, Chambless LE. Classification of heart failure in the Atherosclerosis risk in communities (ARIC) study: a comparison of diagnostic criteria. Circ Heart Fail. 2012; 5:152-159. [PubMed: 22271752]

6. DeFrances CJ, Lucas CA, Buie VC, Golosinskiy A. 2006 National Hospital Discharge Survey. Natl Health Stat Report. 2008; 5:1-20. [PubMed: 18841653]

7. Haldeman GA, Croft JB, Giles WH, Rashidee A. Hospitalization of patients with heart failure: National Hospital Discharge Survey, 1985 to 1995. Am Heart J. 1999; 137:352-360. [PubMed: 9924171] 
8. Lloyd-Jones DM, Larson MG, Leip EP, Beiser A, D’Agostino RB, Kannel WB, Murabito JM, Vasan RS, Benjamin EJ, Levy D. Framingham Heart Study. Lifetime risk for developing congestive heart failure: the Framingham Heart Study. Circulation. 2002; 106:3068-3072. [PubMed: 12473553]

9. Schellenbaum GD, Heckbert SR, Smith NL, Rea TD, Lumley T, Kitzman DW, Roger VL, Taylor HA, Psaty BM. Congestive heart failure incidence and prognosis: case identification using central adjudication versus hospital discharge diagnoses. Ann Epidemiol. 2006; 16:115-122. [PubMed: 15964203]

10. Djousse L, Kochar J, Gaziano JM. Secular trends of heart failure among US male physicians. Am Heart J. 2007; 154:855-860. [PubMed: 17967590]

11. Bahrami H, Kronmal R, Bluemke DA, Olson J, Shea S, Liu K, Burke GL, Lima JA. Differences in the incidence of congestive heart failure by ethnicity: the Multi-Ethnic Study of Atherosclerosis. Arch Intern Med. 2008; 168:2138-2145. [PubMed: 18955644]

12. Bibbins-Domingo K, Pletcher MJ, Lin F, Vittinghoff E, Gardin JM, Arynchyn A, Lewis CE, Williams OD, Hulley SB. Racial differences in incident heart failure among young adults. N Engl J Med. 2009; 360:1179-1190. [PubMed: 19297571]

13. Loehr LR, Rosamond WD, Chang PP, Folsom AR, Chambless LE. Heart failure incidence and survival (from the Atherosclerosis Risk in Communities Study). Am J Cardiol. 2008; 101:10161022. [PubMed: 18359324]

14. Goldberg RJ, Darling C, Joseph B, Saczynski J, Chinali M, Lessard D, Pezzella S, Spencer FA. Epidemiology of decompensated heart failure in a single community in the northeastern United States. Am J Cardiol. 2009; 104:377-382. [PubMed: 19616671]

15. Roger VL, Weston SA, Redfield MM, Hellermann-Homan JP, Killian J, Yawn BP, Jacobsen SJ. Trends in heart failure incidence and survival in a community-based population. JAMA. 2004; 292:344-350. [PubMed: 15265849]

16. Shahar E, Lee S, Kim J, Duval S, Barber C, Luepker RV. Hospitalized heart failure: rates and long-term mortality. J Card Fail. 2004; 10:374-379. [PubMed: 15470646]

17. Goff DC Jr, Pandey DK, Chan FA, Ortiz C, Nichaman MZ. Congestive heart failure in the United States: is there more than meets the I(CD code)? The Corpus Christi Heart Project. Arch Intern Med. 2000; 160:197-202. [PubMed: 10647758]

18. Kalogeropoulos A, Georgiopoulou V, Kritchevsky SB, Psaty BM, Smith NL, Newman AB, Rodondi N, Satterfield S, Bauer DC, Bibbins-Domingo K, Smith AL, Wilson PW, Vasan RS, Harris TB, Butler J. Epidemiology of incident heart failure in a contemporary elderly cohort: the Health, Aging, and Body Composition Study. Arch Intern Med. 2009; 169:708-715. [PubMed: 19365001]

19. Goldberg RJ, Spencer FA, Farmer C, Meyer TE, Pezzella S. Incidence and hospital death rates associated with heart failure: a community-wide perspective. Am J Med. 2005; 118:728-734. [PubMed: 15989906]

20. Chen J, Normand SL, Wang Y, Krumholz HM. National and regional trends in heart failure hospitalization and mortality rates for Medicare beneficiaries. 1998-2008. JAMA. 2011; 306:1669-1678. [PubMed: 22009099]

21. Owan TE, Hodge DO, Herges RM, Jacobsen SJ, Roger VL, Redfield MM. Trends in prevalence and outcome of heart failure with preserved ejection fraction. N Engl J Med. 2006; 355:251-259. [PubMed: 16855265]

22. Steinberg BA, Zhao X, Heidenreich PA, Peterson ED, Bhatt DL, Cannon CP, Hernandez AF, Fonarow GC. for the Get With the Guidelines Scientific Advisory Committee and Investigators. Trends in patients hospitalized with heart failure and preserved left ventricular ejection fraction: prevalence, therapies, and outcomes. Circulation. 2012; 126:65-75. [PubMed: 22615345]

23. Sweitzer NK, Lopatin M, Yancy CW, Mills RM, Stevenson LW. Comparison of clinical features and outcomes of patients hospitalized with heart failure and normal ejection fraction ( $>$ or $=55 \%$ ) versus those with mildly reduced (40\% to 55\%) and moderately to severely reduced $(<40 \%)$ fractions. Am J Cardiol. 2008; 101:1151-1156. [PubMed: 18394450]

24. Yancy CW, Abraham WT, Albert NM, Clare R, Stough WG, Gheorghiade M, Greenberg BH, O'Connor CM, She L, Sun JL, Young JB, Fonarow GC. Quality of care of and outcomes for 
African Americans hospitalized with heart failure: findings from the OPTIMIZE-HF (Organized Program to Initiate Lifesaving Treatment in Hospitalized Patients with Heart Failure) registry. J Am Coll Cardiol. 2008; 51:1675-1684. [PubMed: 18436120]

25. Thomas KL, Hernandez AF, Dai D, Heidenreich P, Fonarow GC, Peterson ED, Yancy CW. Association of race/ethnicity with clinical risk factors, quality of care, and acute outcomes in patients hospitalized with heart failure. Am Heart J. 2011; 161:746-754. [PubMed: 21473975]

26. Joffe SW, Webster K, McManus DD, Kiernan MS, Lessard D, Yarzebski J, Darling C, Gore JM, Goldberg RJ. Improved survival after heart failure: a community-based perspective. J Am Heart Assoc. 2013; 2:e000053. [PubMed: 23676294]

27. McWilliams JM, Meara E, Zaslavsky AM, Ayanian JZ. Differences in control of cardiovascular disease and diabetes by race, ethnicity, and education: U.S. trends from 1999 to 2006 and effects of Medicare coverage. Ann Intern Med. 2009; 150:505-515. [PubMed: 19380852]

28. Hasnain-Wynia R, Baker DW, Nerenz D, Feinglass J, Beal AC, Landrum MB, Behal R, Weissman JS. Disparities in health care are driven by where minority patients seek care: examination of the hospital quality alliance measures. Arch Intern Med. 2007; 167:1233-1239. [PubMed: 17592095]

29. White AD, Folsom AR, Chambless LE, Sharret AR, Yang K, Conwill D, Higgins M, Williams OD, Tyroler HA. Community surveillance of coronary heart disease in the Atherosclerosis Risk in Communities (ARIC) study: methods and initial two years' experience. J Clin Epidemiol. 1996; 49:223-233. [PubMed: 8606324]

30. Fonarow GC, Abraham WT, Albert NM, Stough WG, Gheorghiade M, Greenberg BH, O'Connor CM, Pieper K, Sun JL, Yancy CW, Young JB. OPTIMIZE-HF Investigators and Hospitals. Factors identified as precipitating hospital admissions for heart failure and clinical outcomes: findings from OPTIMIZE-HF. Arch Intern Med. 2008; 168:847-854. [PubMed: 18443260] 


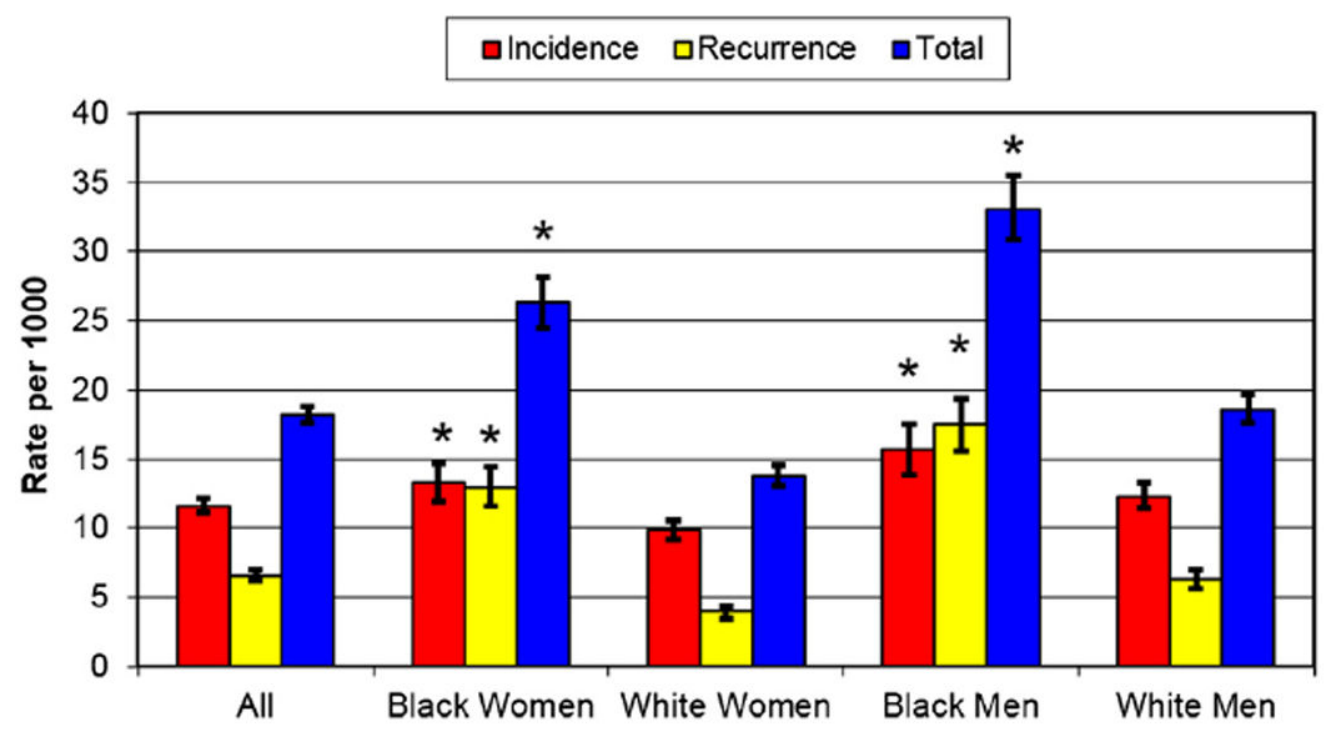

Figure 1.

Age-adjusted rates of first, recurrent, and all hospitalized ADHF events: 2005 to 2009 Atherosclerosis Risk in Communities Heart Failure Community Surveillance. Rates are adjusted for age by the direct method, according to the distribution of the US population in 2000. *p Value <0.05 for the gender-specific comparison between black and white groups. 


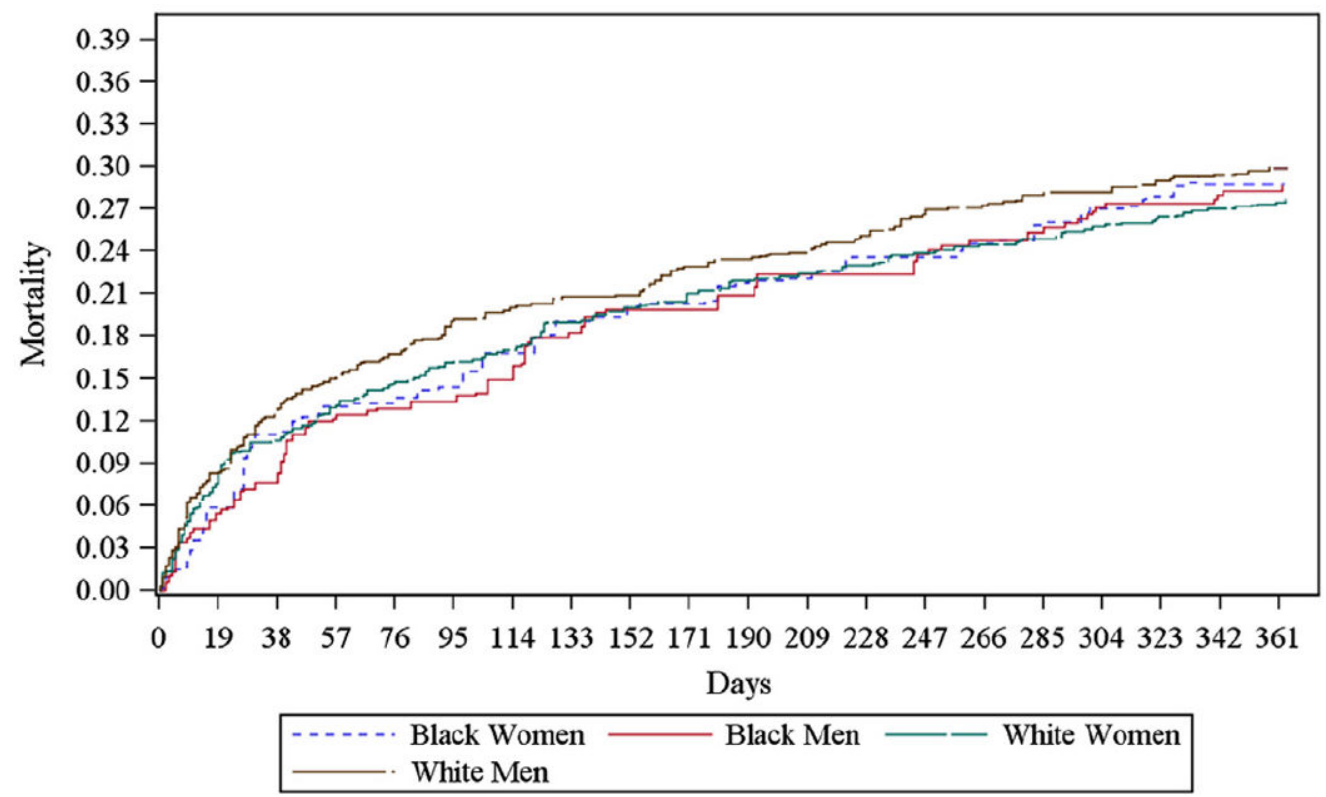

Figure 2.

Age-adjusted 1-year mortality curves for incident hospitalized ADHF cases: 2005 to 2009 Atherosclerosis Risk in Communities Heart Failure Community Surveillance. 

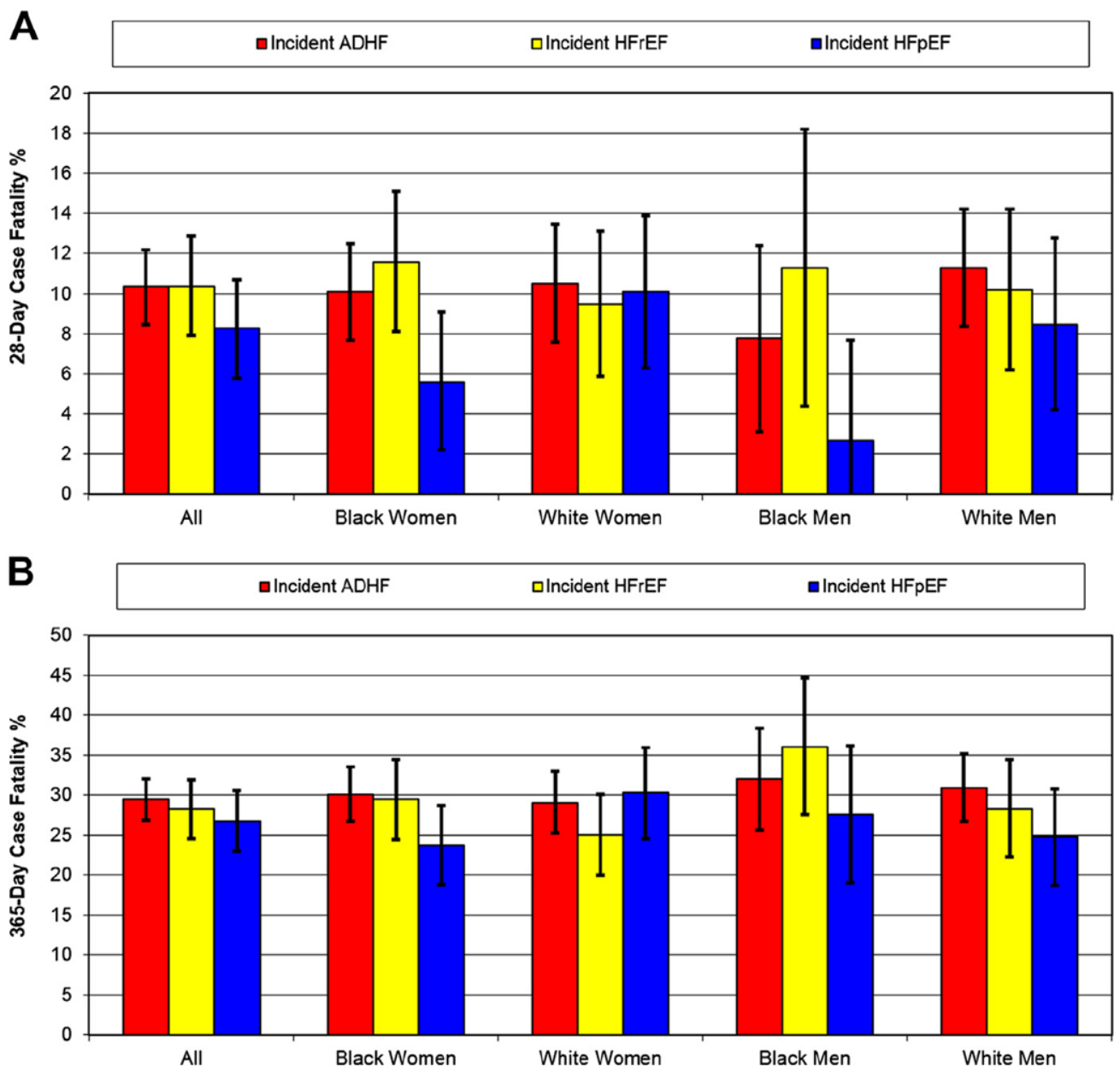

Figure 3.

Age-adjusted (A) 28-day and (B) 365-day CF percentages and 95\% CI for incident hospitalized ADHF cases: 2005 to 2009 Atherosclerosis Risk in Communities Heart Failure Community Surveillance. All percentages are adjusted for age by direct method using the ARIC combined hospitalized HF events as the standard. Gender-specific CF percentages are also adjusted for race. Minor discrepancies with the mortality curve (Figure 2) are because of differences in age-adjustment methods. 
Table 1

Characteristics of the validated hospitalized ADHF cases: 2005 to 2009 Atherosclerosis Risk in Communities Study Heart Failure Community Surveillance

\begin{tabular}{|c|c|c|c|c|}
\hline \multirow[t]{2}{*}{ Variable } & \multicolumn{2}{|c|}{ All ADHF $(n=3,695)$} & \multicolumn{2}{|c|}{$\underline{\text { Incident ADHF }(n=2,252)}$} \\
\hline & Mean or \% & $95 \% \mathrm{CI}$ & Mean or \% & $95 \% \mathrm{CI}$ \\
\hline Age (yrs) & 75.6 & $75.2-75.9$ & 75.9 & $75.5-76.4$ \\
\hline Women & $53.6 \%$ & $52.2-55.1$ & $55.3 \%$ & $53.3-57.3$ \\
\hline Caucasian & $72.4 \%$ & $71.2-73.5$ & $78.5 \%$ & $77.0-80.0$ \\
\hline Black men & $15.2 \%$ & $14.3-16.2$ & $12.2 \%$ & $11.0-13.4$ \\
\hline Black women & $12.4 \%$ & $11.7-13.2$ & $9.3 \%$ & $8.4-10.3$ \\
\hline White men & $38.4 \%$ & $37.0-39.9$ & $43.1 \%$ & $41.1-45.2$ \\
\hline White women & $33.9 \%$ & $32.6-35.3$ & $35.4 \%$ & $33.5-37.4$ \\
\hline Heart function assessed ${ }^{*}, \dagger$ & $90.1 \%$ & $88.9-91.2$ & $88.8 \%$ & $87.1-90.2$ \\
\hline LVEF before hospitalization $(\%)^{*}, \dagger$ & 40.7 & $39.9-41.6$ & 44.2 & $43.1-45.4$ \\
\hline LVEF during hospitalization $(\%)^{*}$ & 41.9 & $41.1-42.7$ & 43.4 & $42.5-44.3$ \\
\hline $\mathrm{HFrEF}$ & $58.3 \%$ & $56.4-60.2$ & $53.0 \%$ & $50.5-55.5$ \\
\hline Previous diagnosis of $\mathrm{HF}$ & $70.1 \%$ & $68.4-71.8$ & $53.2 \%$ & $50.8-55.6$ \\
\hline Body mass index $\left(\mathrm{kg} / \mathrm{m}^{2}\right)^{*}$ & 29.0 & $28.6-29.4$ & 29.2 & $28.8-29.7$ \\
\hline Obesity* & $26.0 \%$ & $24.4-27.6$ & $27.4 \%$ & $25.4-29.6$ \\
\hline Current smoker & $14.2 \%$ & $13.0-15.5$ & $14.8 \%$ & $13.2-16.6$ \\
\hline Hypertension & $83.7 \%$ & $82.2-85.1$ & $83.2 \%$ & $81.2-85.0$ \\
\hline Coronary heart disease & $67.5 \%$ & $65.8-69.1$ & $63.1 \%$ & $60.8-65.3$ \\
\hline Acute MI or unstable angina pectoris & $10.7 \%$ & $9.6-12.0$ & $11.7 \%$ & $10.3-13.4$ \\
\hline Atrial fibrillation or flutter & $35.8 \%$ & $34.1-37.6$ & $31.9 \%$ & $29.7-34.2$ \\
\hline Valvular heart disease & $23.6 \%$ & $22.1-25.2$ & $21.2 \%$ & $19.3-23.2$ \\
\hline Diabetes mellitus & $46.6 \%$ & $44.8-48.4$ & $42.7 \%$ & $40.3-45.1$ \\
\hline Stroke or transient ischemic attack & $20.0 \%$ & $18.5-21.5$ & $20.4 \%$ & $18.5-22.5$ \\
\hline Peripheral vascular disease & $13.9 \%$ & $12.7-15.2$ & $13.2 \%$ & $11.7-14.9$ \\
\hline Asthma or chronic obstructive pulmonary disease & $37.7 \%$ & $35.9-39.5$ & $36.0 \%$ & $33.8-38.4$ \\
\hline Sleep apnea & $9.1 \%$ & $8.1-10.2$ & $8.6 \%$ & 7.4-10.1 \\
\hline Chronic kidney disease $\neq$ & $66.1 \%$ & $64.3-67.8$ & $63.8 \%$ & $61.5-66.0$ \\
\hline
\end{tabular}

The numbers and percentages listed in the table are weighted to account for sampling probabilities (6,168 unweighted sampled events resulting in 3,695 hospitalized ADHF events and 2,252 incident hospitalized ADHF events). Data were available for 100\% of each characteristic except for those noted by "*." The co-morbidities included in this table (such as hypertension and coronary heart disease) were historical diagnoses recorded in the medical record. History of previous HF diagnosis and co-morbidities were obtained from the current hospitalization. Imaging reports of LVEF within 2 years of the current hospitalization were abstracted. Obesity was defined as body mass index $230 \mathrm{~kg} / \mathrm{m}^{2}$.

$\mathrm{MI}=$ myocardial infarction .

$*$

* The percentage of all hospitalized ADHF and all incident ADHF, respectively, with available data for each of the following characteristics: heart function assessed: 90.1\%, 88.8\% ; LVF before hospitalization: 54.3\%, 44.2\% ; LVF during hospitalization: 59.9\%, 64.9\%; and body mass index and obesity: $73.1 \%, 74.0 \%$. 
${ }^{\dagger}$ Assessment of heart function (ventricular systolic and diastolic function) was documented in the medical records (historical reference) or in reports of cardiac imaging (echocardiography, cardiac catheterization, and nuclear or other cardiac imaging tests). If there was more than 1 assessment of LVEF, the lowest value was used.

* Chronic kidney disease was defined as history of dialysis dependence and/or estimated glomerular filtration rate (using the Modification of Diet in Renal Disease method) of $<60 \mathrm{ml} / \mathrm{min} / 1.73 \mathrm{~m}^{2}$. 


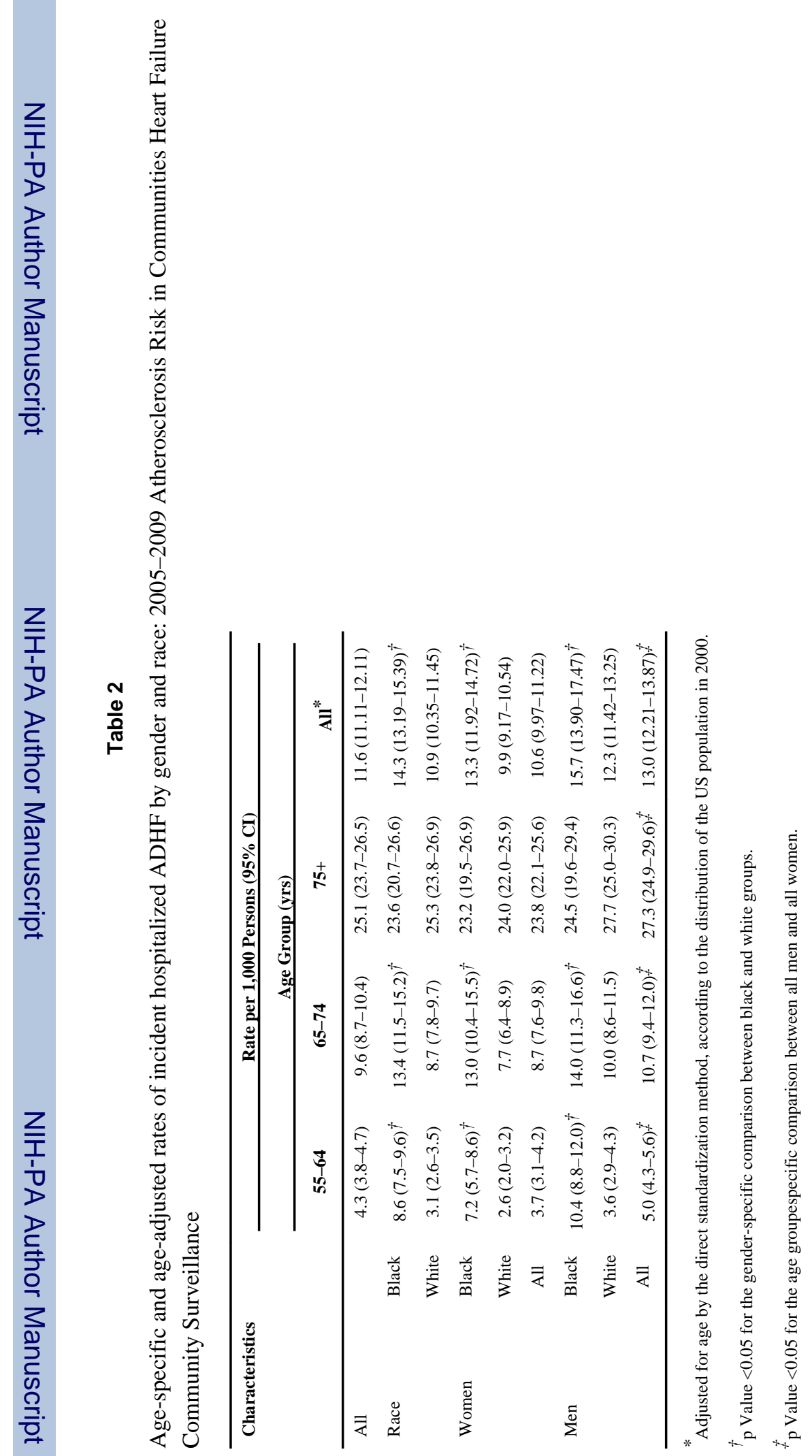




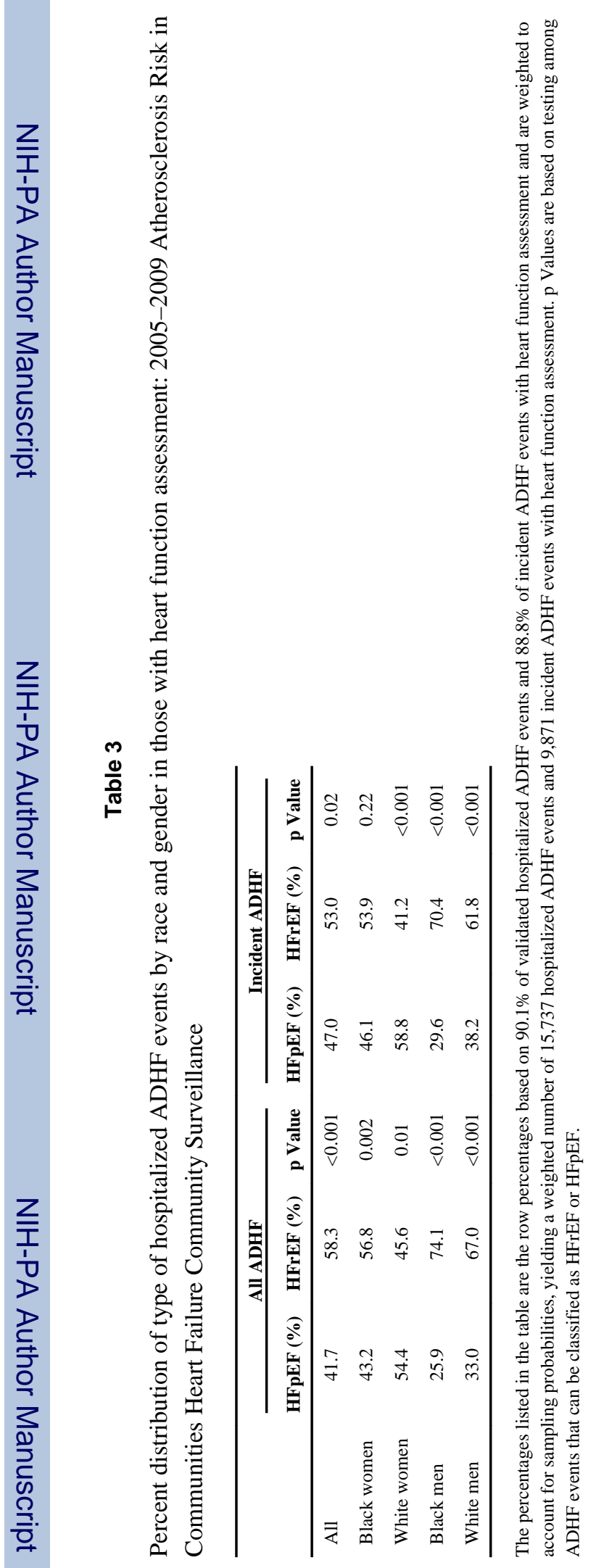

Am J Cardiol. Author manuscript; available in PMC 2015 February 01. 